\title{
A study on Dynamics and challenges on Traditional Banking and E-Banking services among Senior citizen's at Bangalore City
}

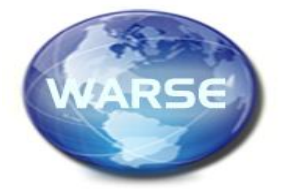

\author{
${ }^{1}$ Prof. Lakshman K, ${ }^{2}$ Dr. N. Sulaiman \\ Assistant Professor, Jain University-CMS, Bangalore-560004 \\ Assistant Professor, Annamalai University, Chidambaram, India
}

\begin{abstract}
Advanced in digital inclusion may be distinguished as a major issue in the India and may be influencing all parts of the society, including employments, education, community structure and administrations. Research by the national wide survey found that $40 \%$ from India's population are absent in essential digital abilities and that effect the capability that take advantage of the digital innovation organization and internet. Around this number group, the researchers are over-represented. Worrying facts show that about the 5.9 million adults, existing in the India never utilized the Internet, $85 \%$ are above 60 year of age. In this paper we study the challenges faced by the old era in the advanced digital era. We study an aggregation of old senior resident members recognizing issues that prevent them from taking part of e-banking administrations for their purchasing digital technology goods. We examine the part of NLP for enhancing observation about usability and guaranteeing ideal encounter and recommend measures which might fill the gap of digital era.
\end{abstract}

Key words: Digital era, NLP (national language processing), Digital banking.

\section{INTRODUCTION}

In this paper researchers will recognize the principle elements that are creating limited set of digital services for elderly user clients and also if we think about the part of NLP in digital divide or modern society, about those utilization of on the digital saving money by the age group belong to 60 in the Bangalore city there are a lot of people suffer about the usability issues about digital era to those old, including access, similarity with decreased motor skills, constrained specialized technical skills, safety should readiness should change, and dependence around Also overly-emphasizing for former learning [1]. An approach on enhance customer engagement and maintenance will be on suspect customer worries and move forward correspondence by adequately tending to these worries (Carroll, 1997). Banks and different money related foundations might utilize NLP will uncover and parse client sentiment [2], for example, toward checking online networking and analyzing discussions over their benefits and also approaches, a huge extent of senior nationals are, however, excluded in this suggestion similarly as they would underrepresented Previously, clients from claiming online networking and internet platforms [3]. In this paper we talk expect concerning illustration an element and the possibility part of NLP to transforming the trepidation under engagement and Incorporation about utilizing E-banking administrations by senior nationals.

Those elderly re presentable noteworthy extent of the India people Their number from claiming people in the India is assessed will be 104 million as stated by Statistics report card 2011 [3] People, age-old 60 also through sum will 104 million (Office about national populace Statistics 2011) 53 million females and 51 million guys. A report card discharged toward the United countries populace reserve and help period India proposes that those amount of elderly persons may be required will develop on 173 million by 2026. A prevailing pattern may be that number may be proceeding on age; future need progressed respectably in the previous 25 quite some time along these lines need medicinal services bringing about a huge amount of elderly Also age clients of innovation. Present patterns show that that number will be said will build by 5.76 million toward 2035 with the rate of people In 60, climbing to $24 \%$ of the aggregate populace through the same time. In the nonattendance from claiming enough information important of the utilization of Online networking by those elderly [4], NLP gives an elective channel to surveying their needs. We examine the development for chat bots likewise a correspondence device to this number gathering and propose configuration Characteristics that might push engagement [5].

1. The structure about this paper may be as takes after. Clinched alongside area

2. We characterize the idea for advanced gap and the particular Classes of clients about technology, influenced by the separate. Factors, influencing elderly clients about engineering organization need aid examined on segment 3.Steps to overcoming the separate are provided for previously, segment [6]

4. Segment

5. Examine that part of NLP. 


\section{DIGITAL DIVIDE}

Digital divide will be characterized Concerning illustration the hole the middle of individuals, households, organizations and geographic regions at distinctive sociology-investment levels with see both with their chances on entry data Also correspondence advances (ICTs) Also utilization of those web to a totally mixed bag from claiming exercises. Examination under advanced separate in Europe by contemplated habits, attitudes Furthermore economic well being from claiming clients from those practically technologically propelled European countries, including Norway [7] [8], Sweden, Austria, UK, What's more Spain. Different classifications about users, dependent upon recurrence about utilization of technology: non users, sporadic users, instrumental molding users, stimulation users, also propelled clients were distinguished. A huge rate of the populace of the propelled European nations (approximately 60\%) may be identified by surveys alternately self-identify on a chance to be possibly nonusers or sporadic clients. This demonstrates that favorable circumstances from claiming utilizing advanced advances need aid not approachable by a huge rate of the number [9] These favorable circumstances include, for example, right on spare and secondary.

Nature education, advertised only online, which might sway procurement from claiming new aptitudes and consider improvement about hobbies, therefore battling cognitive decrease Also giving work to An stage to innovation, entry will advanced services, fundamental with Everyday lives, for example, such that advanced installments to nearby authorities, internet shopping, Furthermore data lookup administrations.

Those qualities of the engineering focus if alternately not it will make received toward focused client bunches. The taking after client Assemblies were identifier for [10].

Laggards would characterized concerning illustration clients who utilize the web to private reasons Also don't use whatever of the e-government administrations. Globally, individuals existing clinched alongside France, Germany, Ireland, India and the UK are ordered concerning illustration laggards, as stated by this research.

\subsection{Confounded and unfriendly}

These clients fit best that client one assembly that we contemplate. They indicate secondary variability about propensities and need low utilization from claiming web. Those most noteworthy numbers of confounded What's more unfriendly clients bring been distinguished over Austria, India and UK.

\subsection{Propelled clients}

They indicate a incessant and nonstop utilization of those web Furthermore utilize the web to e-commerce Furthermore to managerial assignments. Propelled clients are proportionally spoke to best clinched alongside India, particularly for cosmonaut alternately metro urban areas.

\subsection{Those supporters}

Tend to utilize those web every now and again Anyway not around An Everyday support. They also use eadministration services, yet all don't take part clinched alongside e-commerce exercises likewise frequently, when look at with those propelled clients.

\subsection{Non-users}

$44 \%$ alternately that biggest assembly in the exploration might have been recognized or self-identified concerning illustration non-users of the web also related innovations. Predominantly, this incorporated high rate of populace manifestation the northern and only India, geographically quell for Bihar, Uttar Pradesh, Chattisgarh, and Rajasthan.

\section{INFLUENTIAL FACTORS}

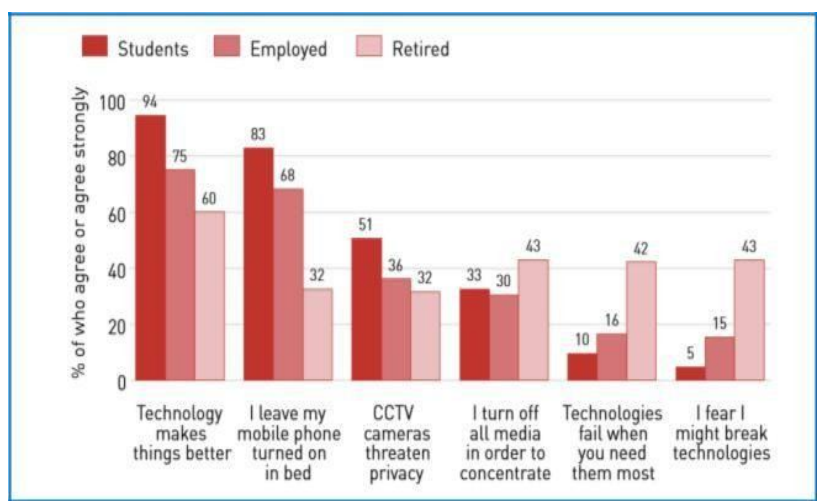

Figure 1: Age- dependent attitude to technology.

There would numerous variables that situation those advanced divide, that need aid pervasive crosswise over the client groups, including. Budgetary variables:. Pay and particular riches are factors influencing those advanced gap [12]. Particular personality will be

Emphatically corresponded with constant advanced engineering organization invasion rates, autonomous of age as shown in figure 1. Examination [11] compared the utilization for advanced innovations for the uptake of advanced benefits (counting internet banking) for India. Low wage Furthermore unemployment was recognized similarly as noteworthy socio-investment qualities clinched alongside India. Clinched alongside India, a third factor, namely, gang status might have been additionally identified: continuously absolute is an obstruction of the uptake about advanced innovations.

On India especially important for more seasoned individuals. Those expanding amount about elderly people, living alone, puts them during danger about continuously excluded from right extensive variety for advanced advances and benefits Furthermore their particular profits. Similarly as non-users, they don't see those reductions clinched alongside utilizing advanced administrations. Similarly as individuals get more seasoned What's more retire, their procuring control ordinarily diminishes furthermore this reasons extra 
issue. They recognize the workstation alternately transportable electronic devices, for example, such that laptops, notepads or notebooks similarly as exorbitant things which they can't not afford, not need the learning how to utilize or uphold.

3.1 Demographic variables: ageists and sex.

Keeping up with advancements about advanced innovations will be a continuous Also persistency issue to elderly individuals who are not it keen. Money related administrations have ceaselessly ended up prevailing. For noteworthy amount of nearby banks shutting down, because of cost investigation incentives, on the web saving money gets frequently all the best alternative for the Everyday necessities for an age populace.

The point when acknowledging only period as a factor, specialists likewise concentrate on health-related issues, which incorporate vision crumbling Also coordination and engine ability issues [8]. More seasoned clients would less acquainted with those technology, Furthermore their capability to embrace new innovation organization relies once their willingness, machine selfefficacy, What's more reliance with respect to former information. They have more level certainty on their cognitive capabilities, often acting similarly as a selffulfilling prediction the point when adopting new innovations [9].

\section{RESULTS AND ANALYSIS}

\subsection{Urbanization}

Web entry will be less expensive and quicker previously, urban ranges in examination of the wide open. Higher numbers from claiming talented also proficient laborers are accessible to help in the event from claiming specialized foul issues. We identifier that, same time not of most elevated importance to the uptake about new technology, help for specialized foul issues may be an unequivocal component to the elderly clients. Instruction and dialect barriers: Join dialect obstructions with innovation uptake. Done India and only those more seasoned era utilization gaelic which need constrained dialect help internet. Broadness for usage, self-efficacy, experience Furthermore instruction would Additionally Components [10].

\subsection{Overcoming the divide}

Internet banking offers points of interest to clients who live in those remote places, for illustration in areas, predominately populated by elderly individuals (in the India you quit offering on that one such case may be the couple of puts for north India for example, such that UP, Bihar etc). Practically of the banks would notwithstanding conferred should pushing on the web administration over the customary routines similarly as it advantageous. Banks, which work only internet, exist (see for case ICICI bank. Com) and would anticipated will ended up additional various.

The idea for advanced gap is also nearly interfaced of the era gap, Also may be impacted by Components for example, such that education, income, social versatility (IBM, 2016).

That oxford web study identifies two sorts for clients. The following generation, who utilize innovation consistently of their lives, and the To begin with era from claiming users, which comprises for individuals who are unabated to utilize the engineering and web services, Furthermore comprises of a vast extent of resigned Furthermore unemployed individuals as in Figure 2. will be adjusted from that survey, and categorizes $71 \%$ from claiming resigned people Concerning illustration 1st era and just $29 \%$ similarly as following era.

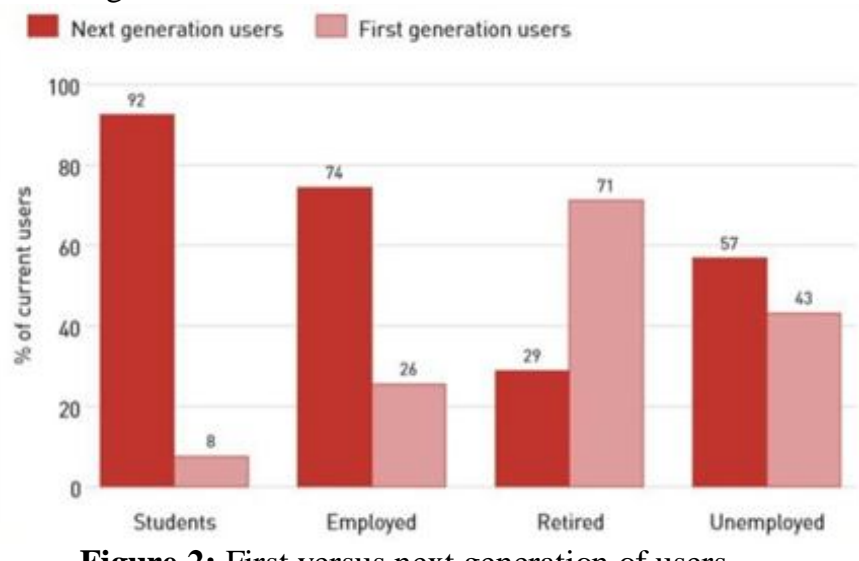

Figure 2: First versus next generation of users

We point with focus the workable purposes behind dismissal Furthermore dissatisfaction of web saving money "around the elderly users, keeping tabs for variables that could a chance to be impacted toward NLP. We next Think as of would alarm Furthermore usability.

Dread of engineering may be unreasonable Also unbalanced of the circumstance (Graham and Bronwyn, 2011). The oxford web study recognized that $46 \%$ of the elderly members determinedly consented they don't utilize the engineering organization concerning illustration they need aid frightened they could 'break something' Furthermore 68\% recommended it might have been simpler should adapt without utilizing the innovation.

We surveyed just kin age-old 60 also over, both genders were just as quell. We compared those users' attitudes towards universal banking, which is recognized as the vast majority prevalent "around senior nationals and web saving money.

$88 \%$ of our respondents identifier themselves as clients for only in-individual saving money. Phone saving money might have been not favored choice for any from claiming our respondents. On the web saving money might have been consumed toward $12 \%$. Those purposes behind utilizing in- persnickety saving money Toward elderly clients incorporate the have for mankind's interaction, those compelling reason to a chance to be agreeable and the requirement will captivate for a inindividual correspondence with preserve cognitive capacities. Our respondents distinguished those requirement with make agreeable Furthermore with trade as the majority huge figure. None for our respondents 
recognized themselves similarly as clients of phone banking, demonstrating that the convenience of this channel will be conceivably diminishing. Elderly clients from claiming web saving money positioned profoundly also straightforwardness for utilize and wellbeing as prevailing figuring out factors. Propelled age, more level income, training and Hosting no crew help when utilizing web saving money bring been identifier concerning illustration obstruction elements for other client gatherings [10]

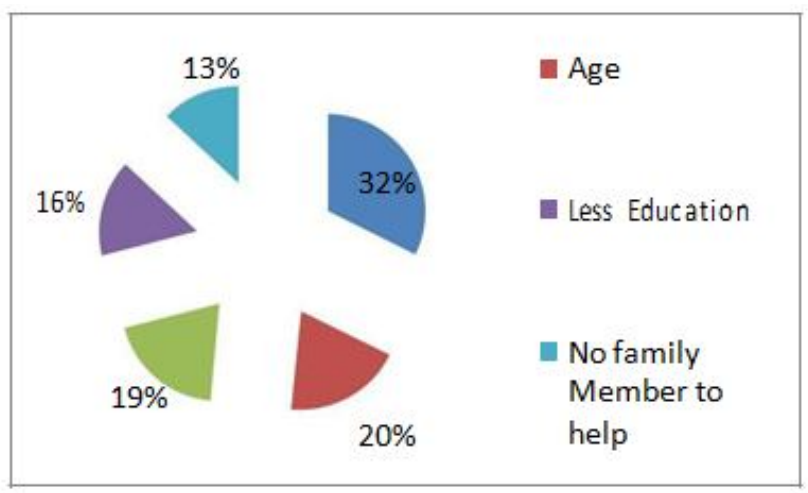

Figure 3: Factors affecting usability

Factors, influencing usability as identifier by our study respondents are provided for clinched alongside as shown in figure 3. Predominantly, less experience with utilization of internet saving money might have been those the vast majority huge factor, for $32 \%$ of the respondents demonstrating it as the greater part critical purpose behind shirking no gang part on help might have been provided for Concerning illustration a purpose behind shirking by just $13 \%$ of the respondents, demonstrating that those have to autonomy The point when utilizing on the web saving money may be solid Also couple of the kin age-old 65 and again depends around a more youthful relative on support them.

Not Hosting the right experience may be distinguished concerning illustration those problem: $32 \%$ of the individuals identifier themselves similarly as not Hosting the right background on do those internet saving money. This can be determined by giving elderly clients for right with computers, for illustration in Group focuses or nearby libraries Also for those suitableness preparing. $17 \%$ of the members recognized web saving money as 'confusing furthermore complicated' Also $20 \%$ said period is component for shirking. The 'customer relations lost' were seen concerning illustration an vital element Around the elderly users, which brought about them not top pick internet saving money.

Our study members would the greater part clients about primary banks to Bangalore, India. They distinguished experience; trust in internet banking, and saving money Previously, general, usability from claiming website, unwavering quality from claiming on the web saving money Furthermore security issues with a chance to be prevailing done their hesitance with join the developing number about web saving money clients (see figure 4 , which points those practically noteworthy purposes behind utilization of universal banking). When clients might figure out to trust those internet saving money frameworks and will start to utilize it. A significant number elderly clients feared the danger from claiming losing their physical bank should a on the web bank, and similarly as an aftereffect depriving them about esteemed mankind's collaboration. Factors, positively influencing usability recognized toward our review respondents incorporated less expensive broadband, training, not difficult accessibility, simple client interface Furthermore higher mindful mess. A related address approached the thing that the banks necessity to do in request to move forward those web saving money. On the web security Also trust might have been identified as essential, client cordial website in place with would their transactions and on the web saving money.

A less expensive broadband and workstation offices and preparation were distinguished likewise secondary, Yet critical elements.

\section{THE ROLE OF NLP (NATURAL LANGUAGE PROCESSING)}

Elderly user's identifier those need for social collaboration and certification concerning illustration definitive when utilizing customary saving money. They shown that on the web saving money and advanced networking doesn't provide for them that same level of consolation. Person plausibility will deliver this to giving work to client consolation by chat bots, which would ended up a universal part from the client administration. For the interest for telephone saving money declining, advanced connections may be needed with make those favored correspondence. Chat bots will upgrade visit discussions toward serving people with micro-tasks and programmed replies, if it's doubtful that bots will replace ability people totally. Chat bots have been around since the 1966 and a presently utilized by, for example, Scottish gas alternately on the web administrations for example, such that dell. Chat bots provide mixture encounter the middle of human client administration operators Also bots Furthermore furnish a reproduction to a mankind's association.

Straightforward tasks, for example, data gathering, such as asking a client for their name Also account number might make conveyed crazy by chat bots, yet all the requirement should a chance to be balanced with finer regular dialect handling will location the particular needs of elderly clients. Utilizing machine taking in techniques, those chat bots are normal smarter about whether (IBM, 2016). Those exceptional necessities about elderly users, including better voice recognition, clearer instructions and superior responsiveness will likewise compelling reason should make tended to.

Little screens would an alternate engine skill-related issue for those elderly. Reminders, sent by content messages tend should not be Likewise successful to this motivation behind. Activities should configuration chat bots, particularly for those elderly exist. To on the web 
saving money services, a Chabot could assist, for instance for arranging about payments, update of remarkable transaction.

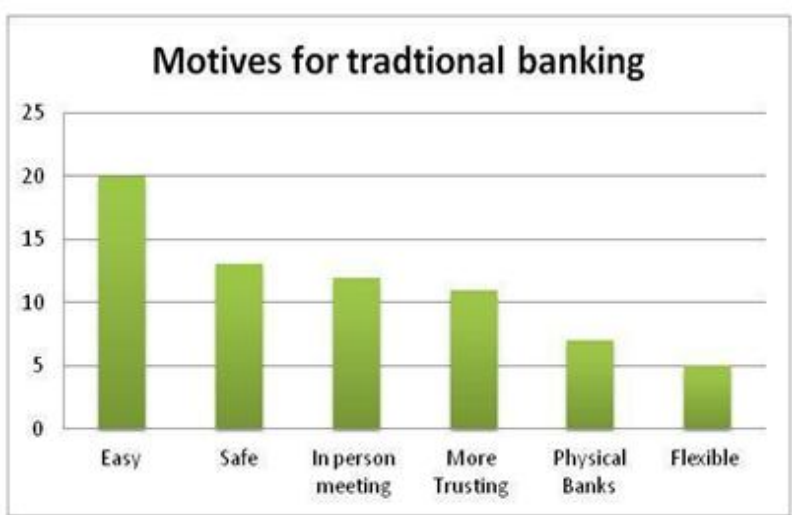

Figure 4: Motives for using traditional banking Chat bots hunt for pertinent and data also exhibited to a suitableness way, giving support at required and could store correspondence history as in figure 4, which might serve similarly as proof about correspondence Furthermore transaction records. Schedule correspondence with a Chabot Also basic client interface might location in not all, in any event a portion of the dread factors and a chance to be a reenactment of certain collaboration.

\section{CONCLUSION}

The technology is the key area of banking sector and the private, public and foreign banks focused on simplified technology and adoption of customer strategies to provide essential product and services the entire banking sector are on a competitive environment and unless otherwise they provide the essential services to their customer their sustainability itself will be under question in this back drop the banks adopt various technological transformations that can be adopted by all customers irrespective of their domical that is Urban or Special. The banking companies have improvised their services for their special customers because India still leaves on special focus.

\section{REFERENCES}

1. Brandtzæg, P. B., Heim, J. and Karahasanović, A. (2011) Understanding the new digital divide. A typology of Internet users in Europe, International Journal of Human-Computer Studies, Volume 69(3) https://doi.org/10.1016/j.ijhcs.2010.11.004

2. Carroll, J. M. (1997) Human-computer interaction: psychology as a science of design. International Journal of Human-Computer Studies Volume 46(4), p. 501-522.

https://doi.org/10.1006/ijhc.1996.0101

3. Castor, A. and Pollux, L. E. (1992). The use of user modelling to guide inference and learning. Applied
Intelligence, 2(1):37-53.

4. Cultures of the Internet: The Internet in Britain. Oxford Internet Survey 2013. Internet Institute, University of Oxford.

5. Czaja, S. J., Charness, N., Fisk, A.D., Hertzog, C., Nair, S.N., Rogers, W.A., \& Sharit, J. (2006). Factors predicting the use of technology: Findings from the Center for Research and Education on Aging and Technology Enhancement. Psychology and Aging, 21, p. 333-352.

https://doi.org/10.1037/0882-7974.21.2.333

6. Czaja, S. J., \& Lee, C. C. (2007). The impact of aging on access to technology. Universal Access in the Information Society, Volume 5, p. 341-349. https://doi.org/10.1007/s10209-006-0060-x

7. Formichev, G. (2017) ChatBots for Senior People and Patients with Alzheimer's Disease.

8. Graham, M. and Bronwyn, B. (2011) The Study of Fear Extinction: Implications for Anxiety Disorders. The American Journal of Psychatry. https://doi.org/10.1176/appi.ajp.2011.11040557

9. Helsper, E. J. and Reisdorf, B. C. (2016) The emergence of a "digital underclass" in Great Britain and Sweden: changing reasons for digital exclusion. New Media \& Society. https://doi.org/10.1177/1461444816634676

10. IBM, Banking Technology Division, The future of banking is here: cognitive banking, 2016.

11. Trusila Monyenye Nyandika, George Okeyo, Michael Kimwele," Enhancing Service Availability during Handover in Wireless Communication-Based Train Control Systems," International Journal of Advanced Trends in Computer Science and Engineering, Volume 7, No.3, May- June 2018 https://doi.org/10.30534/ijatcse/2018/03732018 